\title{
Genetic Characterization of H5N8 Highly Pathogenic Avian Influenza Viruses Isolated from Falcated Ducks and Environmental Water in Japan in November 2020
}

\author{
Ahmed Magdy Khali1 1,2,3 ${ }^{\mathbb{D}}$, Yoshikazu Fujimoto ${ }^{1,4}{ }^{(\mathbb{D}}$, Isshu Kojima ${ }^{4}$, Mana Esaki ${ }^{1}$, Kyonha Ri ${ }^{1}$, \\ Tatsunori Masatani ${ }^{1,2,4}\left(\mathbb{D}\right.$, Tsutomu Matsui ${ }^{5}$ and Makoto Ozawa ${ }^{1,2,4,5, *(D)}$ \\ 1 Joint Faculty of Veterinary Medicine, Kagoshima University, Kagoshima 890-0065, Japan; \\ ahmed.magdy.am549@gmail.com (A.M.K.); k7639981@kadai.jp (Y.F.); k0068103@kadai.jp (M.E.); \\ k6459590@kadai.jp (K.R.); masatani@vet.kagoshima-u.ac.jp (T.M.) \\ 2 United Graduate School of Veterinary Science, Yamaguchi University, Yamaguchi 753-8511, Japan \\ 3 Faculty of Veterinary Medicine, Zagazig University, 44511 Zagazig, Egypt \\ 4 Joint Graduate School of Veterinary Medicine, Kagoshima University, Kagoshima 890-0065, Japan; \\ k3732120@kadai.jp \\ 5 Kagoshima Crane Conservation Committee, Izumi, Kagoshima 899-0208, Japan; \\ crane_c@city.izumi.kagoshima.jp \\ * Correspondence: mozawa@vet.kagoshima-u.ac.jp; Tel.: +81-99-285-3651
}

\section{check for} updates

Citation: Khalil, A.M.; Fujimoto, Y.; Kojima, I.; Esaki, M.; Ri, K.; Masatani, T.; Matsui, T.; Ozawa, M. Genetic Characterization of H5N8 Highly Pathogenic Avian Influenza Viruses Isolated from Falcated Ducks and Environmental Water in Japan in November 2020. Pathogens 2021, 10, 171. https://doi.org/10.3390 /pathogens10020171

Academic Editor: El-Sayed Mohammed Abdel-Whab Received: 26 December 2020 Accepted: 3 February 2021 Published: 4 February 2021

Publisher's Note: MDPI stays neutral with regard to jurisdictional claims in published maps and institutional affiliations.

Copyright: (c) 2021 by the authors. Licensee MDPI, Basel, Switzerland. This article is an open access article distributed under the terms and conditions of the Creative Commons Attribution (CC BY) license (https:/ / creativecommons.org/licenses/by/ $4.0 /)$.

\begin{abstract}
We isolated two highly pathogenic avian influenza viruses (HPAIVs) of subtype H5N8 clade 2.3.4.4b from falcated duck (Anas falcata) feces and environmental water collected at an overwintering site in Japan. Our isolates were almost genetically identical to each other and showed high genetic similarity with H5N8 HPAIVs recently isolated in South Korea, a distant part of Japan, and European countries. These results suggest the potential role of falcated ducks in the dissemination of HPAIVs.
\end{abstract}

Keywords: highly pathogenic avian influenza virus; H5N8; falcated duck

Since the detection of A/Goose/Guangdong/1/1996 (H5N1) (Gs/GD96) from domestic poultry in China in 1996, highly pathogenic avian influenza viruses (HPAIVs) of the H5Nx subtype have been circulating in wild and domestic birds [1]. In addition, the hemagglutinin (HA) of the Gs/GD96 strain has evolved into multiple distinct phylogenetic clades, subclades, and lineages worldwide [2]. Since 2014, H5Nx HPAIVs of clade 2.3.4.4 have been circulating in wild and domestic birds in several countries [3-6], resulting in further classification into four subclades, namely clades 2.3.4.4a-2.3.4.4d [7]. In the winter of 2019/2020, H5N8 HPAIVs belonging to clade 2.3.4.4b caused outbreaks in wild and domestic birds in Europe [8]. Similarly, in the winter of 2020/2021, genetically similar H5N8 HPAIVs from clade 2.3.4.4b were disseminated not only in European countries, but also in South Korea and Japan $[9,10]$, which is most likely due to the migration of wild aquatic birds that are considered natural reservoirs of avian influenza viruses (AIVs) [11], as suggested in previous studies on the dissemination of H5N8 HPAIVs [3-6]. Here, we describe the isolation of two H5N8 HPAIVs clade 2.3.4.4b from a fecal sample of falcated ducks (Anas falcata) and an environmental water sample collected in Japan in November 2020.

The Izumi plain, which is in the Kagoshima Prefecture at the southern tip of Kyushu Island in Japan, is an overwintering site for several tens of thousands of wild migratory birds, including approximately $90 \%$ of the global population of the hooded crane (Grus monachal) and $50 \%$ of the white-naped crane (Grus vipio) [12,13]. Since these two cranes are classified as vulnerable species $[14,15]$, various conservation measures, such as creating artificial wet paddies as roosts, have been conducted every winter. In addition to cranes, wild ducks, including mallards, northern pintails, and Eurasian wigeon, which are considered the primary natural reservoir of AIVs [11], also share this overwintering site [16]. In fact, 
both HPAIVs and low pathogenic AIVs were previously isolated from dead or debilitated cranes, duck feces, and water samples from the Izumi plain $[5,17,18]$.

On 5 November 2020, duck fecal samples were collected by the local government authority at the Komenotsu River mouth, approximately $6 \mathrm{~km}$ away from a crane roost in the Arasaki area, during a public AIV surveillance. Influenza viral RNA was detected in one of the five pooled fecal samples using reverse transcription loop-mediated isothermal amplification (RT-LAMP) at the National Institute for Environmental Studies, as described previously [19]. We then inoculated the AIV gene-positive fecal specimen into embryonated chicken eggs for virus isolation, as described previously [16]. Using the rapid diagnostic test ESPLINE A Influenza (Fujirebio Inc., Tokyo, Japan), the allantoic fluids harvested from the inoculated eggs were found to test positive for influenza A viral antigen. To identify the duck species of the fecal sample, the cytochrome $c$ oxidase I (COI) gene of the mitochondrial DNA was sequenced as described previously [20]. A Basic Local Alignment Search Tool (BLAST) search on the National Center for Biotechnology Information (NCBI) database revealed that the fecal sample was derived from falcated ducks. Subsequent genetic analyses of the allantoic fluid revealed that we isolated an AIV of the H5N8 subtype, named A/falcated duck/KU-d3/2020 (H5N8). Furthermore, on 9 November 2020, we collected environmental water samples from the crane roost in the Arasaki area during a private AIV surveillance and the water samples were subjected to AIV isolation in embryonated chicken eggs, as described previously [17]. We then isolated another H5N8 AIV, named A/environment/Kagoshima/KU-ngr-J2/2020 (H5N8).

To genetically characterize the two $\mathrm{H} 5 \mathrm{~N} 8$ isolates, the nucleotide sequences of all eight gene segments from both isolates were determined (Table 1). The partial sequence of the HA genes showed a cleavage site motif of REKRRKR $\downarrow$ GLF, indicating the high pathogenicity in chickens. All eight gene segments from both isolates were almost identical to each other, with the nucleotide sequences of the HA and M genes from both isolates sharing $100 \%$ identity. These results suggest that feces from falcated ducks are a source of water contamination of crane roosts on the Izumi plain (Table 2).

Table 1. Accession number of each gene segment of the two characterized avian influenza viruses (AIVs).

\begin{tabular}{ccc}
\hline Virus & Gene & Accession No. \\
\hline & PB2 & MW342697* \\
A/falcated duck/KU-d3/2020 (H5N8) & PB1 & MW342698 \\
& PA & MW342699 \\
& HA & MW342700 \\
& NP & MW342701 \\
& NA & MW342702 \\
& M & MW342703 \\
\hline A/environment/Kagoshima/KU-ngr-J2/2020(H5N8) & NS & EPI1815131** \\
\hline & PB2 & EPI1815132 \\
& PB1 & EPI1815133 \\
& PA & EPI1815134 \\
& NA & EPI1815135 \\
& NS & EPI1815137 \\
\hline
\end{tabular}

* Accession numbers in the GenBank database are listed. ${ }^{* *}$ Accession numbers in the GISAID database are listed.

To identify the closest relatives of all the viral gene segments from $\mathrm{A} /$ falcated duck/KUd3/2020 (H5N8) isolate, the sequences were subjected to BLAST search against the Global Initiative on Sharing Avian Influenza Data (GISAID) and NCBI databases (Table 2). 
Table 2. Percent nucleotide identity of A/falcated duck/KU-d3/2020 (H5N8) with its closest relatives.

\begin{tabular}{|c|c|c|c|}
\hline Gene & Accession No.* & Closest Relative ** & Identity (\%) \\
\hline \multirow{4}{*}{ PB2 } & \multirow{4}{*}{ MW342697 } & A/environment/Kagoshima/KU-ngr-J2/2020 (H5N8) & 99.52 \\
\hline & & A/Mandarin duck/Korea/H242/2020 (H5N8) & 99.42 \\
\hline & & A/northern pintail/Hokkaido/M13/2020 (H5N8) & 99.34 \\
\hline & & A/domestic duck/Poland/285/2020 (H5N8) & 99.16 \\
\hline \multirow{4}{*}{ PB1 } & \multirow{4}{*}{ MW342698 } & A/environment/Kagoshima/KU-ngr-J2/2020 (H5N8) & 99.87 \\
\hline & & A/Mandarin duck/Korea/H242/2020 (H5N8) & 99.86 \\
\hline & & A/northern pintail/Hokkaido/M13/2020 (H5N8) & 99.78 \\
\hline & & A/duck/Hungary/1565_20VIR749-2/2020 (H5N8) & 99.42 \\
\hline \multirow{4}{*}{ PA } & \multirow{4}{*}{ MW342699 } & A/environment/Kagoshima/KU-ngr-J2/2020 (H5N8) & 99.91 \\
\hline & & A/Mandarin duck/Korea/H242/2020 (H5N8) & 99.81 \\
\hline & & A/northern pintail/Hokkaido/M13/2020 (H5N8) & 99.81 \\
\hline & & A/domestic goose/Poland/028/2020 (H5N8) & 99.39 \\
\hline \multirow{4}{*}{ HA } & \multirow{4}{*}{ MW342700 } & A/environment/Kagoshima/KU-ngr-J2/2020 (H5N8) & 100.0 \\
\hline & & A/Mandarin duck/Korea/H242/2020 (H5N8) & 99.76 \\
\hline & & A/northern pintail/Hokkaido/M13/2020 (H5N8) & 99.71 \\
\hline & & A/chicken/Germany-BW/AI00049/2020 (H5N8) & 99.53 \\
\hline \multirow{4}{*}{ NP } & \multirow{4}{*}{ MW342701 } & A/environment/Kagoshima/KU-ngr-J2/2020 (H5N8) & 99.87 \\
\hline & & A/Mandarin duck/Korea/H242/2020 (H5N8) & 99.93 \\
\hline & & A/northern pintail/Hokkaido/M13/2020 (H5N8) & 99.80 \\
\hline & & A/chicken/Poland/003/2020 (H5N8) & 99.53 \\
\hline \multirow{5}{*}{ NA } & \multirow{4}{*}{ MW342702 } & A/environment/Kagoshima/KU-ngr-J2/2020 (H5N8) & 99.93 \\
\hline & & A/Mandarin duck/Korea/H242/2020 (H5N8) & 99.57 \\
\hline & & A/northern pintail/Hokkaido/M13/2020 (H5N8) & 99.79 \\
\hline & & A/turkey/Poland/096/2020 (H5N8) & 99.07 \\
\hline & \multirow{4}{*}{ MW342703 } & A/environment/Kagoshima/KU-ngr-J2/2020 (H5N8) & 100.0 \\
\hline \multirow{3}{*}{$\mathrm{M}$} & & A/Mandarin duck/Korea/H242/2020 (H5N8) & 99.89 \\
\hline & & A/northern pintail/Hokkaido/M13/2020 (H5N8) & 99.90 \\
\hline & & A/domestic duck/Poland/271/2020 (H5N8) & 99.79 \\
\hline \multirow{4}{*}{ NS } & \multirow{4}{*}{ MW342704 } & A/environment/Kagoshima/KU-ngr-J2/2020 (H5N8) & 99.88 \\
\hline & & A/Mandarin duck/Korea/H242/2020 (H5N8) & 99.52 \\
\hline & & A/northern pintail/Hokkaido/M13/2020 (H5N8) & 99.52 \\
\hline & & A/turkey/Czech Republic/3071/2020 (H5N8) & 98.92 \\
\hline
\end{tabular}

* Accession numbers in the GenBank database are listed. ** Top four viruses with the highest nucleotide identity found in the GISAID and/or GenBank databases on 2 December 2020 are listed. Note that the top three viruses for all gene segments are our isolate from the environmental water sample, followed by the recent South Korean isolate or the recent isolate from the northern part of Japan.

All eight gene segments from A/falcated duck/KU-d3/2020 (H5N8) showed high similarities (99.34-99.90\%) to their counterparts from two H5N8 HPAIVs of clade 2.3.4.4b isolated in East Asia in October 2020, namely A/Mandarin duck/Korea/H242/2020 (H5N8) [9] and A/northern pintail/Hokkaido/M13/2020 (H5N8) [10]. Although the gene segments from A/falcated duck/KU-d3/2020 (H5N8) also showed high similarity to European poultry isolates from the winter of 2019/2020 [21], they were less similar than those against the Asian isolates. These findings indicated that H5N8 HPAIVs recently isolated in East Asia and Europe share a recent common ancestor without genetic reassortment. These results also confirm the critical role of migratory birds, including the falcated duck, in the dissemination of recent H5N8 HPAIVs.

Falcated ducks, also known as falcated teals, are dabbling ducks that have a wide breeding range spanning eastern Siberia and Mongolia to northeastern China and northern Japan, with wintering grounds in southeast Asia to eastern India [22]. Hence, falcated ducks are considered one of the migratory ducks that may facilitate the dissemination of AIVs through their migratory flyways. In fact, falcated ducks, along with other wild birds, were implicated in the dissemination of H5N8 HPAIVs in East Asia during the outbreak in South Korea in January 2014 [3]. However, falcated ducks are a minor duck species that host AIVs: among 18,502 AIVs isolated from duck species deposited in the GISAID database as of 9 December 2020, only $0.037 \%$ were associated with falcated duck, whereas more AIVs were isolated from mallards $(30.82 \%)$, northern pintails $(4.79 \%)$, and Eurasian wigeons $(0.28 \%)$. These three duck species can be also observed at the Izumi plain every winter as stated above. More importantly, A/falcated duck/KU-d3/2020 (H5N8) is the 
first falcated duck isolate in Japan. Our findings imply the potential of falcated ducks as one of the migratory ducks facilitating the dissemination of AIVs to Japan.

In conclusion, we isolated two H5N8 HPAIVs clade 2.3.4.4b from falcated duck feces and environmental water collected at an overwintering site for wild migratory birds in Japan in November 2020. Genetic analyses revealed that our isolates were almost identical, suggesting the potential of feces from falcated ducks as a source of environmental water contamination. In addition, the genomes of our isolates shared high similarity with those from H5N8 HPAIVs recently isolated in South Korea and the northern part of Japan, Hokkaido, implying the potential role of falcated ducks in the dissemination of HPAIVs. Our results highlight the importance of global surveillance of AIVs.

Author Contributions: Conceptualization, A.M.K. and M.O.; methodology, A.M.K. and M.O.; investigation, A.M.K., Y.F., I.K., M.E., K.R. and M.O.; resources, T.M. (Tsutomu Matsui); data curation, A.M.K. and M.O.; writing—original draft preparation, A.M.K.; writing—review and editing, T.M. (Tatsunori Masatani) and M.O.; supervision, M.O.; project administration, T.M. (Tsutomu Matsui) and M.O.; funding acquisition, M.O. All authors have read and agreed to the published version of the manuscript.

Funding: This research was funded by the Environment Research and Technology Development, grant number JPMEERF18S20104.

Institutional Review Board Statement: All experimental protocols were approved by the Genetic Modification Experiment Safety Committee (approval number: 24044) and Pathogens Safety Management Committee (approval number: 302), Kagoshima University and confirmed by the Minister of Education, Culture, Sports, Science and Technology (2 September 2019).

Data Availability Statement: The data that support the findings of this study are openly available in the GenBank at https:/ / www.ncbi.nlm.nih.gov/genbank/, reference numbers MW342697-MW342704 and in the GISAID database at https: / / www.gisaid.org/, reference numbers EPI1815131-EPI1815138.

Acknowledgments: We thank Satoru Taura and Naoko Maruta of the Division of Gene Research, Research Support Center, Kagoshima University and Natsuko Nishi of the Joint Faculty of Veterinary Medicine, Kagoshima University for technical assistance. We thank the Ministry of the Environment, the Prefecture of Kagoshima, and the City of Izumi for their kind cooperation. This work was supported by the contracted research activity for crane conservation with the City of Izumi, Japan. This research was commissioned by the Kagoshima Crane Conservation Committee.

Conflicts of Interest: The authors declare that the research was conducted in the absence of any commercial or financial relationships that could be construed as a potential conflict of interest.

\section{References}

1. Smith, G.J.; Donis, R.O.; World Health Organization/World Organisation for Animal Health; Food and Agriculture Organization (WHO/OIE/FAO) H5 Evolution Working Group. Nomenclature updates resulting from the evolution of avian influenza A(H5) virus clades 2.1.3.2a, 2.2.1, and 2.3.4 during 2013-2014. Influenza Other Respir. Viruses 2015, 9, 271-276. [CrossRef] [PubMed]

2. WHO; OIE; FAO. H5N1 Evolution Working Group. Toward a unified nomenclature system for highly pathogenic avian influenza virus (H5N1). Emerg. Infect. Dis. 2008, 14, 1. [CrossRef] [PubMed]

3. Zhou, L.; Liu, J.; Pei, E.; Xue, W.; Lyu, J.; Cai, Y.; Wu, D.; Wei, W.; Liu, Y.; Jin, H.; et al. Novel Avian Influenza A(H5N8) Viruses in Migratory Birds, China, 2013-2014. Emerg. Infect. Dis. 2016, 22, 1121-1123. [CrossRef] [PubMed]

4. Jeong, J.; Kang, H.M.; Lee, E.K.; Song, B.M.; Kwon, Y.K.; Kim, H.R.; Choi, K.S.; Kim, J.Y.; Lee, H.J.; Moon, O.K.; et al. Highly pathogenic avian influenza virus (H5N8) in domestic poultry and its relationship with migratory birds in South Korea during 2014. Vet. Microbiol. 2014, 173, 249-257. [CrossRef] [PubMed]

5. Ozawa, M.; Matsuu, A.; Tokorozaki, K.; Horie, M.; Masatani, T.; Nakagawa, H.; Okuya, K.; Kawabata, T.; Toda, S. Genetic diversity of highly pathogenic H5N8 avian influenza viruses at a single overwintering site of migratory birds in Japan, 2014/15. Euro. Surveill. 2015, 20, 21132. [CrossRef] [PubMed]

6. Yehia, N.; Naguib, M.M.; Li, R.; Hagag, N.; El-Husseiny, M.; Mosaad, Z.; Nour, A.; Rabea, N.; Hasan, W.M.; Hassan, M.K.; et al. Multiple introductions of reassorted highly pathogenic avian influenza viruses (H5N8) clade 2.3.4.4b causing outbreaks in wild birds and poultry in Egypt Infection. Gen. Evol. 2018, 58, 56-65. [CrossRef] [PubMed]

7. WHO. Antigenic and Genetic Characteristics of Zoonotic Influenza A Viruses and Development of Candidate Vaccine Viruses for Pandemic Preparedness. Available online: https://www.who.int/influenza/vaccines/virus/characteristics_virus_vaccines/en/ (accessed on 25 December 2020). 
8. OIE. Updates on Avian Influenza in Animals (types H5 and H7). Available online: https://www.oie.int/en/animal-health-inthe-world/update-on-avian-influenza/2020 / (accessed on 25 December 2020).

9. Jeong, S.; Hun, L.D.; Hoon, K.J.; Jin, K.Y.; Hak, L.S.; Andrew, Y.C.; Hyeon, K.T.; Eun, P.J.; Song-I, L.; Seon, S.C. Highly Pathogenic Avian Influenza Clade 2.3.4.4b Subtype H5N8 Virus Isolated from Mandarin Duck in South Korea, 2020. Viruses 2020, 12, 1389. [CrossRef] [PubMed]

10. Isoda, N.; Twabela, A.T.; Bazarragchaa, E.; Ogasawara, K.; Hayashi, H.; Wang, Z.-J.; Kobayashi, D.; Watanabe, Y.; Saito, K.; Kida, H.; et al. Re-Invasion of H5N8 High Pathogenicity Avian Influenza Virus Clade 2.3.4.4b in Hokkaido, Japan, 2020. Viruses 2020, 12, 1439. [CrossRef] [PubMed]

11. Webster, R.G.; Bean, W.J.; Gorman, O.T.; Chambers, T.M.; Kawaoka, Y. Evolution and ecology of influenza A viruses. Microbiol. Rev. 1992, 56, 152-179. [CrossRef] [PubMed]

12. Yasuhiro, Y. Hooded Crane Nabe-zuru (Jpn) Grus monacha. Bird Res. News Japan Bird Res. Assoc. 2017, 4, 1. Available online: http://www.bird-research.jp/1_shiryo/seitai/nabezuru.pdf (accessed on 25 December 2020).

13. Mutsuyuki, U. White naped-crane Manazuru (Jpn) Grus Vibio. Bird Res. News Japan Bird Res. Assoc. 2010, 7, 1. Available online: http:/ / www.bird-research.jp/1_shiryo/seitai/mana.pdf (accessed on 25 December 2020).

14. BirdLife International. Grus monacha. The IUCN Red List of Threatened Species 2016. Available online: https:/ / www.iucnredlist. org/species / 22692151/93337861 (accessed on 25 December 2020).

15. BirdLife International. Antigone vipio. The IUCN Red List of Threatened Species, 2018. Available online: https://www. iucnredlist.org/species/22692073/131927305 (accessed on 25 December 2020).

16. Okuya, K.; Kanazawa, N.; Kanda, T.; Kuwahara, M.; Matsuu, A.; Horie, M.; Masatani, T.; Toda, S.; Ozawa, M. Genetic characterization of an avian H4N6 influenza virus isolated from the Izumi plain, Japan. Microbiol. Immunol. 2017, 61, 513-518. [CrossRef] [PubMed]

17. Okuya, K.; Kawabata, T.; Nagano, K.; Kohara, T.; Kusumoto, I.; Takase, K.; Ozawa, M. Isolation and characterization of influenza A viruses from environmental water at an overwintering site of migratory birds in Japan. Arch. Virol. 2015, 160, 3037-3052. [CrossRef] [PubMed]

18. Khalil, A.M.; Nishi, N.; Kojima, I.; Fukunaga, W.; Kuwahara, M.; Masatani, T.; Matsui, T.; Ozawa, M. Transition in genetic constellations of H3N8 and H4N6 low-pathogenic avian influenza viruses isolated from an overwintering site in Japan throughout different winter seasons. Arch. Virol. 2020, 165, 643-659. [CrossRef] [PubMed]

19. Onuma, M.; Kakogawa, M.; Yanagisawa, M.; Haga, A.; Okano, T.; Neagari, Y.; Okano, T.; Goka, K.; Sakawa, M. Characterizing the temporal patterns of avian influenza virus introduction into Japan by migratory birds. J. Vet. Med. Sci. 2017, 79, 943-951. [CrossRef] [PubMed]

20. Hebert, P.D.; Stoeckle, M.W.; Zemlak, T.S.; Francis, C.M. Identification of Birds through DNA Barcodes. PLoS Biol. $2004,2,312$. [CrossRef] [PubMed]

21. Śmietanka, K.; Świętoń, E.; Kozak, E.; Wyrostek, K.; Tarasiuk, K.; Tomczyk, G.; Konopka, B.; Welz, M.; Domańska-Blicharz, K.; Niemczuk, K. Highly pathogenic avian influenza H5N8 in Poland in 2019-2020. J. Vet. Res. 2020, 64, 469-476. [CrossRef] [PubMed]

22. Rutgers, A.; Norris, K.A. Bronze-capped teal. In Encyclopedia of Aviculture, 1st ed.; Blandford Press: London, UK, 1970; Volume 1, pp. 127-128. 